\title{
Occupational Mercury Exposure at a Thermometer Facility — Jiangsu Province, 2019
}

\author{
Yanqiong $\mathrm{Xu}^{1}$; Xiaoling Zhang ${ }^{1}$; Yiliang Xin ${ }^{1}$; Xiaowen Liu'; Xing Sheng'; \\ Enmin Ding'; Jingxin Xie ${ }^{1}$; Lei Han ${ }^{1}$; Hengdong Zhang ${ }^{1}$; Xin Liu ${ }^{1, *}$
}

\begin{abstract}
Summary
What is already known about this topic?

Mercury is still used in the manufacture of some thermometers in China. This may pose health risks if exposure is not properly prevented and controlled.

What is added by this report?

An onsite investigation of a workplace at a thermometer facility in Jiangsu Province in 2019 found heavily elevated airborne and urinary mercury levels among a massive number of workers exposed to mercury. Traditional and obsolete technology as well as inadequate protection measures for occupational hazards caused this high level of exposure.

What are the implications for public health practice?

Employers at thermometer producing facilities need to adopt effective protection measures and implement strict management. Monitoring exposure, adopting better engineering controls, diligent cleaning, and providing recommended personal protective equipment (PPE) along with training to their workers properly can alleviate mercury exposure at their facilities. In addition, transitioning to mercury-free thermometers would eliminate the risk of mercury exposure.
\end{abstract}

On November 25, 2019, the Jiangsu Health Commission contacted the Jiangsu Provincial CDC (JSCDC) seeking assistance for an investigation of mercury exposure among workers at a thermometer manufacturing facility. For 3 consecutive years, nearly all workers who were tested had urine mercury levels far exceeding the biological exposure limit (BEL) of $35.0 \mu \mathrm{g} / \mathrm{g}$ creatinine (Cr) required by China's National Health Commission (NHC). Thermometers were composed of a slender glass tube containing liquid mercury. During production, inhalation of mercury vapor and direct contact of mercury via skin were likely the main routes of exposure. JSCDC investigators took industrial hygiene sampling, obtained ventilation measurements, and observed field conditions as well as work practices. Inorganic mercury vapor concentrations were found to exceed the occupational exposure limits (OELs) at 15 of 18 workstations in the small thermometer department. Workers wore inadequate personal protective equipment (PPE). Moreover, the facilities and measures for controlling occupational hazards should be upgraded so that the released vapors can be effectively isolated or removed. Employees who are at risk for mercury exposure should have access to and consistently wear NHC-approved respirators to protect against mercury vapor and nitrile or other suitable gloves to prevent contact exposure.

\section{INVESTIGATION AND RESULTS}

On December 3, 2019, JSCDC and the local occupational health administration carried out a supervised investigation to assess the work environment, interview employees, and perform mercury monitoring at the workplace. First, the urine testing results for three consecutive years were collected. A case of mercury exposure was defined as a urinary mercury level above the NHC BEL of $35.0 \mu \mathrm{g} / \mathrm{g}$ Cr. Workers who received confirmation of mercury exposure were referred to an occupational disease diagnosis agency for further evaluation. Subsequently, the air mercury exposure level of workers in the workplace was tested by obtaining air samples near the individual breathing zone with a lowflow pump and analyzed using atomic fluorescence spectrometry. The NHC currently recommends that exposure to inorganic mercury be limited to $0.02 \mathrm{mg} / \mathrm{m}^{3}$ as an 8-hour time-weighted average (TWA), as well as $0.04 \mathrm{mg} / \mathrm{m}^{3}$ as a short-term exposure limit (STEL). In addition, ventilation measurements were performed using a TSI 8347 (TSI, Inc., USA) air velocity meter at workstations with local exhaust ventilation systems. All workers were required to participate in a survey including the employment history, PPE use, and medical and social history. 
The enterprise under investigation was established in 2008 to manufacture glass thermometers and acupuncture needles for clinical use. The company employed approximately 120 workers involved in 2 assembly lines (trigonal and internal scaling) of glass thermometers (Table 1). Nearly 15 million small thermometers were produced each year in the manufacturing zone, which occupies 6,150 square meters $\left(\mathrm{m}^{2}\right)$ covering 2 floors of the plant. Several operations were contained in the process of manufacturing thermometers except for glass tubes, which were pre-manufactured by another company and purchased for further assembly. In brief, reservoir bulbs were blown at one end of cut-glass tubes and were then filled with liquid mercury. Any excess liquid was driven out with heat and the tubes were flamesealed to a certain length. The sealed tubes were calibrated, mounted on a scale, assembled on or in a holder as necessary, and packaged. Trigonal and internal scaling thermometers were the two predominant models produced at this company.

Initially, urine mercury (standardized to urinary $\mathrm{Cr}$ ) results were collected from 2016-2018 (Table 2). The median level for workers exposed to mercury was 670.4 (97.9-1705.7) $\mu \mathrm{g} / \mathrm{g} \mathrm{Cr}$ in 2016, 311.1 (37.3995.2) $\mu \mathrm{g} / \mathrm{g}$ Cr in 2017, and 160.7 (2.9-899.3) $\mu \mathrm{g} / \mathrm{g}$ $\mathrm{Cr}$ in 2018. With urine mercury decreasing year by year on average, it was still far beyond the normal reference value. Evidence of chronic mercury poisoning commences at levels in excess of $35 \mu \mathrm{g} / \mathrm{g} \mathrm{Cr}$. By

TABLE 1. The results of air sampling for inorganic mercury in the thermometer factory workplace — Jiangsu Province, 2019.

\begin{tabular}{|c|c|c|c|c|}
\hline \multirow{2}{*}{ Division } & \multirow{2}{*}{ Job Category } & \multicolumn{2}{|c|}{ Air $\mathrm{Hg}$ concentration $\left(\mathrm{mg} / \mathrm{m}^{3}\right)$} & \multirow{2}{*}{ Judgement } \\
\hline & & $\mathrm{C}_{\mathrm{TWA}}$ & $\mathrm{C}_{\text {STEL }}$ & \\
\hline \multirow{10}{*}{ Trigonal thermometer } & Distillation & 0.083 & 0.135 & unqualified \\
\hline & Fill and degas & 0.057 & 0.072 & unqualified \\
\hline & Contractor & 0.045 & 0.053 & unqualified \\
\hline & Centrifuge & 0.067 & 0.102 & unqualified \\
\hline & Inspector & 0.079 & 0.107 & unqualified \\
\hline & Pull-Top & 0.052 & 0.062 & unqualified \\
\hline & Pointer & 0.091 & 0.074 & unqualified \\
\hline & Scaling & 0.066 & 0.074 & unqualified \\
\hline & Printing and baking & 0.063 & 0.063 & unqualified \\
\hline & Package & 0.060 & 0.070 & unqualified \\
\hline \multirow{8}{*}{ Internal scaling thermometer } & Fill and degas & 0.030 & 0.037 & unqualified \\
\hline & Contractor & 0.028 & 0.028 & unqualified \\
\hline & Pointer & 0.024 & 0.028 & unqualified \\
\hline & Scaling & 0.019 & 0.020 & qualified \\
\hline & Inserting marker & 0.016 & 0.019 & qualified \\
\hline & Sealing & 0.020 & 0.024 & qualified \\
\hline & Inspector & 0.028 & 0.029 & unqualified \\
\hline & Package & 0.029 & 0.028 & unqualified \\
\hline \multirow{4}{*}{ Flat handle needle (free of $\mathrm{Hg}$ ) } & Embossing & 0.010 & 0.022 & qualified \\
\hline & Pulling and cutting & 0.007 & 0.010 & qualified \\
\hline & Inspector & 0.009 & 0.011 & qualified \\
\hline & Storage & 0.019 & 0.026 & qualified \\
\hline \multirow{4}{*}{$\mathrm{Hg}$ free thermometer (free of $\mathrm{Hg}$ ) } & Glass tube & 0.010 & 0.012 & qualified \\
\hline & Fill and degas & 0.004 & 0.005 & qualified \\
\hline & Pointer & 0.018 & 0.020 & qualified \\
\hline & Combination & 0.016 & 0.031 & qualified \\
\hline
\end{tabular}

Abbreviation: $\mathrm{Hg}=$ mercury, $\mathrm{C}_{\mathrm{TWA}}=$ concentration-time weighted average, $\mathrm{C}_{\mathrm{STEL}}=$ concentration-short term exposure limit. 
TABLE 2. Urinary mercury levels by current job category from workers at the thermometer facility — Jiangsu, 2019.

\begin{tabular}{|c|c|c|c|c|c|c|c|}
\hline \multirow{2}{*}{ Division } & \multirow{2}{*}{ Job category } & \multicolumn{3}{|c|}{ Urine $\mathrm{Hg}(\mu \mathrm{g} / \mathrm{g} \mathrm{Cr})$ : Median (Range) } & \multicolumn{3}{|c|}{ Excess ratio (\%) } \\
\hline & & 2016 & 2017 & 2018 & 2016 & 2017 & 2018 \\
\hline \multirow{9}{*}{ Trigonal thermometer } & Fill and degas & $906.4(401.0-1460.8)$ & $532.4(527.9 \sim 886.0)$ & $401.7(291.4-507.6)$ & 100 & 100 & 100 \\
\hline & Contractor & 791.9(444.6-1705.7) & $335.5(297.5-920.2)$ & $374.1(55.6-846.7)$ & 100 & 100 & 100 \\
\hline & Centrifuge & 377.5 & 624.6 & 113.0 & 100 & 100 & 100 \\
\hline & Inspector & $572.8(191.0-726.9)$ & $310.8(139.4-434.7)$ & $78.1(69.2-232.1)$ & 100 & 100 & 100 \\
\hline & Pull-Top & 460.4 & 439.6 & 324.1 & 100 & 100 & 100 \\
\hline & Pointer & $908.9(315.3-1390.4)$ & $208.9(80.5-726.9)$ & $257.7(161.1-817.6)$ & 100 & 100 & 100 \\
\hline & Scaling & $859.4(545.8-1449.2)$ & $364.0(66.2-995.2)$ & $345.6(2.9-610.1)$ & 100 & 100 & 87.5 \\
\hline & Printing and baking & $665.0(97.9-1175.5)$ & 318.3(95.2-639.2) & $249.2(62.8-899.3)$ & 100 & 100 & 100 \\
\hline & Package & $404.6(347.1-526.7)$ & $316.4(187.6-596.7)$ & $160.3(141.8-366.3)$ & 100 & 100 & 100 \\
\hline \multirow{4}{*}{ Internal scaling thermometer } & Fill and degas & $841.5(289.3-1440.7)$ & $378.6(165.6-805.9)$ & 251.3(85.9-423.3) & 100 & 100 & 100 \\
\hline & Contractor & 445.6 & 130.7 & 128.4 & 100 & 100 & 100 \\
\hline & Pointer & 807.7(190.8-1393.6) & $698.0(621.5-894.7)$ & $237.8(87.1-413.2)$ & 100 & 100 & 100 \\
\hline & Scaling & $1210.4(260.6-1243.0)$ & $260.0(58.4-346.6)$ & $39.2(12.0-167.3)$ & 100 & 100 & 71.4 \\
\hline \multirow{4}{*}{ Internal scaling thermometer } & Inserting marker & 463.8 & 171.2 & 152.1 & 100 & 100 & 100 \\
\hline & Sealing & 208.5 & 340.3 & 76.3 & 100 & 100 & 100 \\
\hline & Inspector & 1334.4 & 249.8(196.4 855.6) & 108.0(17.9-159.3) & 100 & 100 & 66.7 \\
\hline & Package & $346.2(230.6-461.8)$ & $242.9(115.4-971.0)$ & $84.2(47.5-120.7)$ & 100 & 100 & 100 \\
\hline N/A & Jobs free of $\mathrm{Hg}$ & $\mathrm{N} / \mathrm{A}$ & N/A & $0.11(0.01-1.08)$ & $\mathrm{N} / \mathrm{A}$ & N/A & 0 \\
\hline
\end{tabular}

Abbreviation: $\mathrm{Hg}=$ mercury, $\mathrm{Cr}=$ creatinine, $\mathrm{N} / \mathrm{A}=$ not applicable.

constrast, unexposed individuals rarely exhibit mercury-in-urine concentrations in excess of $1.0 \mu \mathrm{g} / \mathrm{g} \mathrm{Cr}$.

Then according to GBZ 159-2004 (Specifications of air sampling for hazardous substances monitoring in the workplace) (1) and GBZ/T 300.18-2017 (Determination of toxic substances in workplace air Part 18: Mercury and its compounds) (2), ambient air sampling of the workplace was implemented using a GilAir-5 (Sensidyne, Inc., USA) sampler $(0.5 \mathrm{~L} / \mathrm{min})$. All production areas of the facility were sampled on whether there was direct mercury exposure or not. Overall, it was indicated that inorganic mercury vapor concentrations ranged from 0.016 to $0.091 \mathrm{mg} / \mathrm{m}^{3}$ (median: $0.049 \mathrm{mg} / \mathrm{m}^{3}$ ) for concentration-time weighted average $\left(\mathrm{C}_{\text {TWA }}\right)$ and 0.019 to $0.135 \mathrm{mg} / \mathrm{m}^{3}$ (median: $0.058 \mathrm{mg} / \mathrm{m}^{3}$ ) for concentration-short term exposure limit $\left(\mathrm{C}_{\mathrm{STEL}}\right)$ (Table 1$)$. That is, approximately $83.3 \%(15 / 18)$ of the work positions exceeded the limits given by GBZ 2.1-2019 (Occupational exposure limits for hazardous agents in the workplace - Part 1: Chemical hazardous agents) (3). However, the sampling results among workers in mercury-free sites only averaged $0.01 \mathrm{mg} / \mathrm{m}^{3}$ for $\mathrm{C}_{\text {TWA }}$ and $0.016 \mathrm{mg} / \mathrm{m}^{3}$ for $\mathrm{C}_{\mathrm{STEL}}$.
The workshop deployed two axial fans creating rated airflows of $14,000 \mathrm{~m}^{3} / \mathrm{h}$ and $7,670 \mathrm{~m}^{3} / \mathrm{h}$. The air purification system was formed by connecting the exhaust hoods above different positions with pipelines and equipped with active carbon to absorb mercury vapor, while waste gases from combustion were extracted and directly discharged outside. The actual airflows created by the exhaust system were found to be unsatisfactory as the wind speed at control points under each hood was far below the capture velocity of $200 \mathrm{fpm}(1.016 \mathrm{~m} / \mathrm{s})$ necessary to control mercury vapors (Supplementary Table S1 available in http:// weekly.chinacdc.cn/). Due to the small size and excessive height of the hood opening, the design of the exhaust hood for mercury distillation was insufficient, which affected the actual protective ability of the equipment (Figure 1A).

Other control measures applied throughout the factory include isolating equipment, submerging broken thermometers in trays of water, and conducting a continuous clean-up program. During the field investigation, some engineering facilities appeared to run in poor condition. The size of the isolation cabinet did not fit well with the degassing machine, leaving doors not fully closed (Figure 1B). Furthermore, 


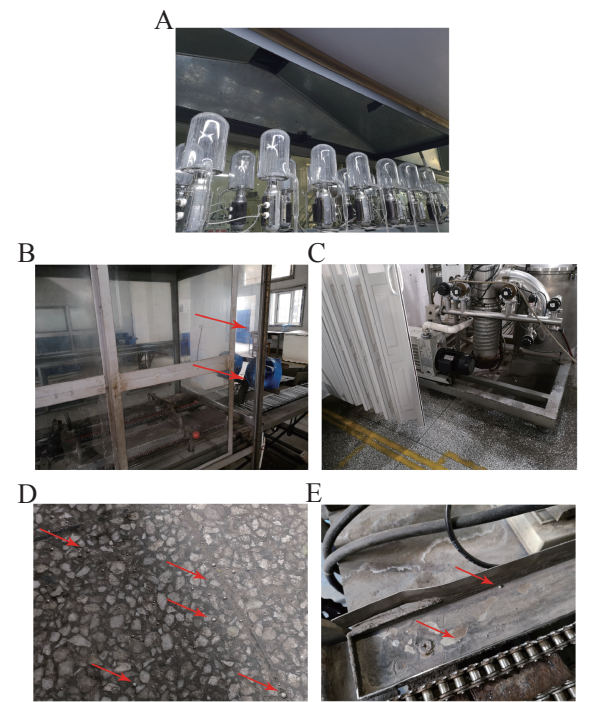

FIGURE 1. The working environment and status of engineering control measures during field investigations at a thermometer facility in Jiangsu Province in 2019. (A) Exhaust hoods for mercury distillation; (B) The door of isolation cabinet did not fit the degassing machine (red arrows indicate a large gap between the door and its frame); (C) A plastic screen was half-open in front of the filling machine; (D) Spills of mercury on the ground (red arrows indicate mercury droplets); (E) Small droplets of mercury on the machine (red arrows indicate mercury droplets)

though a plastic screen was set up in front of the filling machine, it was not effectively enclosed (Figure 1C).

The employer distributed disposable active carbon facepieces for workers exposed to mercury before 2019. Since then, half facepieces (3M Reusable Respirator 7502 adapted with 3M Mercury Vapor Cartridge 6009 and $3 \mathrm{M}$ Particulate Filter 5N11) were provided. The cartridge and particulate filter were planned to be replaced once a month and once a week, respectively. However, owing to a lack of supervision on PPE wearing, it was found the respiratory protective masks did not fit several workers well.

During our survey, we realized that occupational safety and health regulations were not satisfactorily implemented. Small droplets of mercury contamination were obviously visible on the grounds and machines (Figure 1D-1E).

\section{DISCUSSION}

Mercury can evaporate at room temperature and at higher rates at higher temperatures (4). Environmental data demonstrated that workers had significant exposure to inorganic mercury vapor at the thermometer plant. Many samples, including individuals and environments, exceeded the NHC compulsory standard of $0.02 \mathrm{mg} / \mathrm{m}^{3}$ (TWA) and/or $0.04 \mathrm{mg} / \mathrm{m}^{3}$ (STEL). In addition, continual urinalysis accurately depicted increasing trends in an employee's mercury absorption, which manifested an increased risk of adverse health effects to workers. Thus, the occupational hazards of mercury could not be overlooked, especially in certain outdated industries.

For the sake of minimizing occupational health risks, the most effective measure was to renovate the production process, such as taking indium as a substitute for mercury (5). But the employer's top priority was to enhance engineering and administrative controls to reduce mercury contamination. Urine mercury and personal breathing-zone mercury vapor levels were recommended to be periodically monitored. Local ventilation devices need to be repositioned, better enclosed, or otherwise modified until a minimum capture velocity of $200 \mathrm{fpm}$ can be achieved and maintained. When respirators were used, a formal respiratory protection program comprising of written standard operating procedures (SOP) must be established in accordance with GB 2626-2019 (Respiratory protection - Non-powered air-purifying particle respirator) (6). The procedures should cover specific requirements for respirator use, selection, cleaning, inspection, maintenance, training, and supervision. Moreover, spills or droplets of mercury must be immediately cleaned up with a vacuum system equipped with an absorbent filter. All operations involving mercury should be performed over impermeable surfaces without crevices. Most importantly, the enterprise must take the primary responsibility of occupational health management and reinforce daily supervision. Workers must receive sufficient training against the health hazards of mercury, as well as the work practices and personal hygiene measures necessary to avoid occupational hazards. This training is extremely important for new employees to prevent the development of sloppy habits in handling mercury. Through these measures, the level of mercury exposure can be lowered.

Acknowledgment: We thank Zhigang $\mathrm{Li}$ and Hongqun Zhang for their assistance during the field investigation.

Funding: This work was supported by Science and Education Promotion Project of JSCDC (JKRC2016015).

Conflicts of interest: No conflicts of interest were reported. 
doi: $10.46234 / \mathrm{ccdcw} 2020.172$

\# Corresponding author: Xin Liu, liux@jscdc.cn.

1 Department of Occupational Disease Prevention and Control, Jiangsu Provincial Center for Disease Control and Prevention, Nanjing, Jiangsu, China; ${ }^{2}$ Department of Technique Service, Jiangsu Provincial Center for Disease Control and Prevention, Nanjing, Jiangsu, China.

Submitted: June 18, 2020; Accepted: July 29, 2020

\section{REFERENCES}

1. National Occupational Health Standards Committee. GBZ 159-2004 Specifications of air sampling for hazardous substances monitoring in the workplace. Beijing: People's Medical Publishing House, 2006. http://www. csres.com/detail/121066.html. (In Chinese).
2. National Health and Family Planning Commission of PRC. GBZ/T 300.18-2017 Determination of toxic substances in workplace air-Part 18: mercury and its compounds. Beijing: Standards Press of China, 2017. http://www.csres.com/detail/306664.html. (In Chinese).

3. National Health Commission. GBZ 2.1-2019 Occupational exposure limits for hazardous agents in the workplace-Part 1: chemical hazardous agents. Beijing: Standards Press of China, 2019. http://www.csres.com/ detail/332305.html. (In Chinese).

4. Bjørklund G, Dadar M, Mutter J, Aaseth J. The toxicology of mercury: current research and emerging trends. Environ Res 2017;159:545 - 54. http://dx.doi.org/10.1016/j.envres.2017.08.051.

5. Chandler JE, Messer HH, Ellender G. Cytotoxicity of gallium and indium ions compared with mercuric ion. J Dent Res 1994;73(9):1554 9. http://dx.doi.org/10.1177/00220345940730091101.

6. State Administration of Market Supervision and Administration, Standardization Administration of China. GB 2626-2019 Respiratory protection-non-powered air-purifying particle respirator. Beijing Standards Press of China; 2019. http://www.csres.com/detail/ 336274.html. (In Chinese). 
SUPPLEMENTARY TABLE S1. Ventilation detection on local exhausting devices at the thermometer facility in Jiangsu, 2019.

\begin{tabular}{|c|c|c|c|c|c|}
\hline \multirow{2}{*}{ Division } & \multirow{2}{*}{ Job/Location } & \multirow{2}{*}{ Local exhausting } & \multicolumn{3}{|c|}{ Wind velocity $(\mathrm{m} / \mathrm{s})$} \\
\hline & & & 1 & 2 & 3 \\
\hline \multirow{7}{*}{ Trigonal thermometer } & \multirow{2}{*}{ Distillation } & Exhaust hood 1 & 0.02 & 0.03 & 0.02 \\
\hline & & Exhaust hood 2 & 0.03 & 0.02 & 0.03 \\
\hline & \multirow{3}{*}{ Fill and degas } & Bulb machine & 0.42 & 0.43 & 0.43 \\
\hline & & Degassing machine 1 & 0.17 & 0.18 & 0.17 \\
\hline & & Degassing machine 2 & 0.13 & 0.14 & 0.12 \\
\hline & Contractor & Contractor machine & 0.23 & 0.25 & 0.24 \\
\hline & Pull-Top & Pull-Top machine & 0.20 & 0.21 & 0.22 \\
\hline \multirow{2}{*}{ Internal scaling thermometer } & \multirow{2}{*}{ Sealing } & Sealing machine 1 & 0.03 & 0.04 & 0.04 \\
\hline & & Sealing machine 2 & 0.18 & 0.19 & 0.19 \\
\hline
\end{tabular}

